\title{
Humidity-controlled phase transitions of Amorphous Ca-Mg Carbonates (ACMC)
}

\author{
AVNI PATEL ${ }^{1}$, SIOBHAN WILSON ${ }^{1}$, MAIJA RAUDSEPP ${ }^{1}$ \\ AND ANNA HARRISON ${ }^{2}$ \\ ${ }^{1}$ University of Alberta \\ ${ }^{2}$ Géosciences Environnement Toulouse (GET) - CNRS \\ Presenting Author: avni1@ualberta.ca
}

In recent decades, experimental and theoretical studies of nucleation of $\mathrm{Ca}-\mathrm{Mg}$ carbonates have challenged classical crystallisation theory. Non-classical crystallisation describes the formation of crystals by assimilation of particles including multiion complexes and nanoparticles that may exist in amorphous, crystalline or liquid forms ${ }^{1}$. In carbonate systems, crystallisation via an amorphous precursor is increasingly recognised as a ubiquitous process in biotic and abiotic precipitation. Amorphous $\mathrm{Ca}-\mathrm{Mg}$ carbonates (ACMC) can undergo a series of transformations through metastable intermediate phases until the most stable crystalline configuration is obtained. The lifetime of the amorphous precursors and the composition of crystalline phases along the pathway are affected by temperature, $\mathrm{Mg}^{2+}$ aqueous concentrations, $\mathrm{HCO}^{3-} / \mathrm{CO}_{3}{ }^{2-}$ ratios and the presence of stabilising additives ${ }^{2,3}$. However, few studies have considered the role of water activity on crystallization rate and pathway. Here, we present data on the transformation products of ACMC under variable humidity conditions. Amorphous starting materials were synthesised by rapidly mixing $0.25 \mathrm{M}(\mathrm{Ca}, \mathrm{Mg}) \mathrm{Cl}_{2}$ and $0.25 \mathrm{M}$ $\mathrm{Na}_{2} \mathrm{CO}_{3}$ solutions at $21.0 \pm 0.8{ }^{\circ} \mathrm{C}$. The dry solids were placed under relative humidity $(\mathrm{RH})$ conditions varying from $5 \pm 2 \%$ to $98 \pm 1 \%$ controlled using saturated salt solutions and removed for analysis at time intervals of 14, 30, 132 and 180 days. Complementary X-ray Diffraction (XRD), Scanning Electron Microscopy (SEM) images and Energy Dispersive X-ray Spectroscopy (EDS) data revealed the enhanced stability of amorphous phases at low relative humidities. At RH $>95 \%$, the onset of crystallisation occurs before 14 days. After 30 days, SEM data capture the initial development of diverse crystalline morphologies, whilst XRD data show the co-occurrence of multiple $\mathrm{Ca}-\mathrm{Mg}$ carbonate phases. Following 132 days at $\mathrm{RH}>$ 95\%, SEM images show larger, more euhedral crystals and reveal spatial relationships between distinct end-member phases and XRD confirms the continued presence of multi-phase assemblages. These findings offer important insights into cation transport and mineral phase transformation reactions mediated by nanometre scale water films at carbonate mineral surfaces.

References

[1] De Yoreo, J. J. et al.(2015) Science (80-. ). 349, aaa6760 aaa6760.

[2]Purgstaller et al., (2019) CrystEngComm 21, 155-164

[3]Xto, J. M. et al. (2019) Cryst. Growth Des. 19, 4385-4394 